\title{
BENTUK PENYAJIAN DAN FUNGSI MUSIK DALAM UPACARA THAU CHIT PADA AGAMA KHONGHUCU DI YAYASAN BUDI MULIA KECAMATAN LUBUK PAKAM KABUPATEN DELI SERDANG
}

\author{
Kristian Sinaga \\ Prodi Pendidikan Musik
}

\begin{abstract}
Presentation Form And Function In Ceremony Thau Music Chit On Confucian Religion in Yayasan Budi Mulia Lubuk Pakam District of Deli Serdang. Faculty of Language and Art. State University of Medan. This study aims to determine rites Chit Thau, the usefulness of the instrument, the form of presentation and function of music in Chit Thau ceremony at the Confucian religion in Yayasan Budi Mulia Lubuk Pakam District of Deli Serdang. This study is based on a theoretical foundation that explains the sense of form, sense of presentation, understanding the function, understanding music, understanding, Thau ceremony Chit, and understanding of Confucianism. This research was conducted at Yayasan Budi Mulia Lubuk pakam District of Deli Serdang in June to August 2015. The method in this research use descriptive qualitative research methods. The population in this study is saikong (prayer leaders), community, and musicians at the ceremony Thau Chit Confucian Religion in Yayasan Budi Mulia Lubuk Pakam District of Deli Serdang, while samples totaling 28 people. Data collected through observation, interviews, documentation, and strudi literature. These results indicate that the rites Thau Chit divided into eight parts, namely Huat Piau is cleaning the altar and sending letters to the god of hell. Wang Pai is a tribute to the gods of heaven. Old Phou is the process invites the god of the earth. Tiau Hun is the process of summoning spirits. Mong Ek is the process of bathing spirit. Iok Pai Wang is a tribute to the god of medicine. Sio Ui house burning spirit. And Koei Kio is the return of the spirit of the gods .. Uses istrument music at the ceremony Thau Confucianism is Choei Chit Khin and $\mathrm{Er} \mathrm{Hu}$ as a carrier melody, as rithem drums, bells and la Bua carrier tempo. Form of presentation of the music at the ceremony Thau Chit Confucianism is divided into three parts, namely musical homage to the gods, notification to the spirit, and the spirit returns to music. There are three functions of the music at the ceremony Thau Chit Confucianism, which is a function of aesthetic pleasure and emotional expression, communication function and endorsement of religious rituals and functions contributes to the continuity and stability of culture.
\end{abstract}

Keywords: Presentation Form, Function, Ceremony Thau Chit 


\section{A. PENDAHULUAN}

\section{Latar Belakang Masalah}

Manusia merupakan mahkluk yang memiliki akal pikiran untuk melakukan inovasi-inovasi dalam mencapai tujuan tertentu sesuai yang diinginkannya. Di dalam proses pencapaian inovasi tersebut manusia kerap menggunakan kreativitas untuk menciptakan suatu hal yang baru. Setiap manusia juga dapat berkreasi melalui media yang berbeda-beda sesuai dengan kemampuan dan bakatnya masing-masing. Banyak orang beranggapan bahwa musik merupakan suatu hiburan atau hobby untuk sekedar menyalurkan bakat yang dimiliki setiap orang. Namun disamping itu, perlu kita ketahui bahwa musik juga memiliki pengaruh yang besar dalam perkembangan zaman. Bukan hanya sekedar menjadi hiburan, hobby atau sumber penghasilan, kini musik mengambil peranan yang sangat penting dalam kehidupan manusia baik dalam kegiatan sosial, budaya, pendidikan, kesehatan, ekonomi, bahkan agama. Kebudayaan yang terus menerus dilakukan oleh sekelompok orang akan menimbulkan suatu kepercayaan yang dianggap sekelompok masyarakat tersebut sebagai ritual yang harus dilaksanakan. Di zaman sekarang, kepercayaan itu bergeser menjadi suatu ajaran yang dapat kita kenali dengan istilah ajaran agama.

- Pada agama Khonghucu, musik sangat berperan dalam setiap upacara keagamaan, seperti; kelahiran, pernikahan, dan kematian. Agama Khonghucu sedikit berbeda dengan agama yang lain dalam konteks upacara kematian. Kelompok yang menganut agama khonghucu ini, disamping mereka telah melakukan upacara kematian, ada juga upacara penting yang harus dilakukan oleh pihak keluarga yang ditinggalkan. Upacara yang dilakukan keluarga yang ditinggalkan itu dinamakan upacara Thau Chit. Thau Chit merupakan upacara untuk mengirimkan doa kepada keluarga yang telah meninggal dunia. Upacara ini dilakukan setelah tujuh atau empat puluh Sembilan hari yang terhitung sejak meninggal dunia. Pada Umumnya, masyarakat Tionghoa yang beragama Khonghucu seperti masyarakat di daerah Kecamatan 
Lubuk Pakam, Kabupaten Deli berdampingan dengan agama yang Serdang sampai saat ini masih lain.

melakukan upacara ini sebagai bentuk penghormatan kepada orang yang telah meninggal dunia yang dilakukan di Yayasan Budi Mulia. Dalam upacara Thau Chit tersebut, musik mempunyai peranan penting sebagai pengiring pengantar doa yang dibawakan oleh Saikong (pemimpin doa).

Dalam hal ini, alat musik yang digunakan adalah alat musik tradisional yang berasal dari Cina. Dalam bentuk Penyajian musik pada upacara Thau Chit, seluruh pemain musik memainkan alat musik dengan mengikuti irama dan melodi yang dinyanyikan oleh Saikong (pemimpin doa). Berdasarkan bentuk penyajian musik dalam upacara Thau Chit, terdapat fungsi musik yang sangat penting untuk mengiringi proses upacara. Sampai saat ini, umat Khonghucu di Kecamatan Lubuk Pakam masih tetap menggunakan musik tradisional dalam setiap upacara Thau Chit meskipun agama Khonghucu sudah hidup
Tujuan yang ingin dicapai dalam penelitian ini adalah untuk mengetahui bentuk penyajian dan fungsi musik dalam upacara Thau Chit pada agama Khonghucu di Kecamatan Lubuk Pakam Kabupaten Deli Serdang.

\section{Landasan Teori}

Untuk membahas struktur bentuk penyajian dan fungsi musik dalam upacara Thau Chit pada agama Khonghucu di Kecamatan Lubuk Pakam Kabupaten Deli Serdang beberapa teori yaitu teori bentuk, penyajian, fungsi, musik, dan dibantu oleh teori Upacara Thau Chit.

\section{Metodologi Penelitian}

Metodologi penelitian adalah sesuatu alat atau cara untuk melakukan pemeriksaan yang teliti. Penyelidikan atau kegiatan pengumpulan data, pengolahan data yang dilakukan secara sistematis dan objektif untuk memecahkan masalah persoalan praktik. Dengan demikian penulis suatu penelitian harus dapat menghasilkan kajian yang bersifat 
objektif, sistematis, dan logis. Untuk mencapai tujuan penelitian yang diinginkan, haruslah menggunakan metode yang sesuai dengan metode yang diteliti agar kegiatan penelitian dapat berhasil dengan baik. Menurut Maryaeni (2005:60), data penelitian kualitatif biasanya berupa tulisan, secara langsung, gambar, angka, pertunjukan kesenian, relief-relief dan berbagai bentuk data lain yang bisa ditranposisikan sebagai teks, data tersebut bisa bersumber dari hasil survei, observasi, wawancara, dokumentasi, rekaman, hasil evaluasi dan sebagainya. Maka dari pendapat tersebut penelitian ini dilakukan dengan menggunakan metode deskriptif dengan pendekatan kualitatif. Hal ini dilakukan untuk memperoleh informasi yang diperlukan dalam penelitian.

\section{Lokasi dan Waktu Penelitian}

Sesuai dengan judul penelitian di atas lokasi penelitian dilakukan di Yayasan Budi Mulia Kecamatan Lubuk Pakam Kabupaten Deli Serdang. Waktu penelitian dilakukan sejak pertengahan bulan Juni sampai dengan bulan Agustus 2015.

\section{Populasi Dan Sampel}

1) Populasi

Populasi dalam penelitian merupakan hal yang sangat penting untuk menentukan beberapa jumlah populasi sesuai dengan data yang akan dikumpulkan. Sugiono (2012:297) yang menyatakan bahwa “ populasi diartikan sebagai wilayah generalisasi yang terdiri atas : objek/subjek yang mempunyai kualitas dan karakteristik tertentu yang ditetapkan oleh peneliti untuk dipelajari dan kemudian ditarik kesimpulannya".

Berdasarkan dengan penelitian ini, maka yang menjadi populasi dalam penelitian ini adalah seluruh pemain musik yang berjumlah 3 orang, pesereta berjumlah 23 orang, pengurus yayasan 2 orang, dan pemimpin doa yang berjumlah 2 orang, sehingga jumlah populasinya adalah 30 orang.

2) Sampel

Sampel adalah bagian dari jumlah dan karakteristik yang dimiliki oleh populasi tersebut. Untuk itu sampel yang diambil dari populasi 
harus betul-betul representatif diperoleh di lapangan dicatat, (mewakili). Dalam menentukan kemudian hasil akan dianalisis sampel penelitian, penulis dengan secermat mungkin. didalam berpedoman kepada pendapat Hidayat penelitian ini akan diupayakan untuk (2007:133) yang mengatakan bahwa: "Sampel adalah bagian atau wakil populasi yang diteliti”.

Berdasarkan pendapat diatas maka yang menjadi sampel adalah seluruh pemain musik, peserta upacara dan saikong (pemimpin doa) yang berjumlah 30 orang yang ada di Yayasan Budi Mulia Lubuk Pakam. Jadi sampel yang diambil adalah sampel total, karena jumlah populasi kurang dari 100 orang.

\section{Teknik Pengumpulan Data}

Teknik pengumpulan data yang dilakukan adalah sebagai berikut:

1. Observasi

2. Wawancara

3. Dokumentasi

4. Studi Kepustakaan

\section{Teknik Analisis Data}

Dalam Penelitian ini menggunakan analisis data kualitatif yang terkumpul melalui studi kepustakaan, observasi, wawancara, dokumentasi. Semua data yang

memperdalam secara spesifik dalam rangka menjawab keseluruhan pertanyaan penelitian. Di samping itu, langkah-langkah ini dapat menjadi koreksi atau alat kontrol terhadap berbagai kekurangan data yang terkumpul yang selanjutnya dapat dilengkapi. Semua data yang diperoleh dari tempat penelitian dicatat, kemudian diolah dan dianalisis dengan teliti. Hasil olahan data dan analisis tersebut akan dijadikan sebagai bahan tulisan yang nantinya dapat ditemukan kesimpulan yang akan dirumuskan.

\section{B. ISI}

\section{A. Yayasan Sosial Budi Mulia}

\section{Lubuk Pakam}

Yayasan sosial pada umumnya memiliki peranan yang penting dalam kehidupan masyarakat. Yayasan sosial juga dapat berfungsi untuk memenuhi kebutuhan masyarakat. Seperti yang di lakukan Yayasan Budi Mulia yang terletak di Jalan Bakaran 
Batu No. 4 Kecamatan Lubuk Pakam. Sesuai wawancara dengan narasumber Timbul Kusnadi, SE, SH, M.Kn ( wawancara 27 Juni 2015 ) menjelaskan tentang yayasan Budi Mulia sebagai berikut :

Yayasan Budi Mulia Lubuk Pakam dulunya disebut rumah miskin yang didirikan pada tahun 1956 , Pendirinya bernama Tok Kie Chiang. Yayasan Budi Mulia sudah empat kali melakukan pergantian pengurus, hingga saat ini Yayasan dipimpin oleh bapak EK Jam. Sejarah berdirinya bangunan tersebut semula diperuntukkan sebagai penampungan masyarakat Tiongkok yang tidak mampu untuk kembali ke negaranya, dikarenakan masa kontrak kerja kepada perusahaan perkebunan milik Belanda telah habis. Seiring berjalannya waktu, setelah semua masyarakat Tiongkok yang ditampung dirumah miskin tersebut telah meninggal dunia maka pengurus rumah miskin ini bermusyawarah untuk mengalihfungsikan rumah miskin bukan lagi sebagai tempat penampungan melainkan tempat persemayaman dan pelaksanaan upacara-upacara agama Khonghucu.
Dan mulai saat itu, rumah miskin berganti nama dengan Yayasan Sosial Budi Mulia.

\section{Tata Upacara Thau Chit Pada} Agama Khonghucu Di Yayasan Budi Mulia Kecamatan Lubuk Pakam Kabupaten Deli Serdang

\section{Huat Piau}

Huat piau merupakan ritual pertama yang dilakukan pada upacara Thau Chit. Huat Piau merupakan proses pembersian altar dan tempat diselenggarakan upacara Thau Chit.

2. Pai Wang

Pai Wang merupakan ritual kedua yang dilakukan pada upacara Thau Chit. Pai Wang merupakan proses memberikan penghormatan kepada dewa-dewa surga untuk meminta agar dosa-dosa roh yang telah meninggal tersebut dapat dihapuskan.

\section{Phou Tua}

Merupakan ritual ketiga yang dilakukan pada upacara Thau Chit. Phou tua merupakan proses menggundang seluruh dewa bumi.

\section{Tiau Hun}

Tiau Hun merupakan ritual keempat yang dilakukan pada upacara Thau Chit. Tiau hun merupakan proses 
memanggil roh seseorang yang telah meninggal.

\section{Mong Ek}

Mong Ek merupakan ritual kelima yang dilakukan pada upacara Thau Chit. Mong Ek merupakan proses memandikan roh agar bersih dari dosa-dosa.

\section{Pai Iok Wang}

Pai Iok Wang merupakan ritual ke enam yang dilakukan pada upacara Thau Chit. upacara Pai Iok Wang merupakan penghormatan kepada dewa obat, yang artinya selama masa sakit orang yang telah meninggal dunia itu telah mendapatkan bantuan dari dewa obat sehingga dapat bertahan hidup.

\section{Sio Ui}

Sio Ui merupakan ritual ketujuh yang dilakukan pada upacara Thau Chit. Sio Ui merupakan proses pembakaran rumah yang terbuat dari kertas.

\section{Koei Kio}

Koei Kio merupakan ritual terakhir yang dilakukan pada upacara Thau Chit. koei kio merupakan proses pengembalian roh ke Nirwana.
Instrument musik yang digunakan pada saat Upacara Thau Chit agama Khonghucu di Yayasan Budi Mulia Kecamatan Lubuk Pakam Kabupaten Deli Serdang

1. Lonceng

Lonceng adalah alat musik yang terbuat dari logam kuningan, dan untuk memainkan alat musik ini dapat dilakukan dengan cara dipukul. Pada alat musik ini hanya saikong lah yang dapat menggunakan alat tersebut. Fungsi alat musik ini dipercaya sebagai alat pemanggil arwah.

\section{Simbal}

adalah alat musik yang terbuat dari logam kuningan, bentuknya bulat seperti lingkaran, memiliki dua bagian yang sama. Cara memainkanya dengan memukul antara kedua sisi alat musik tersebut, dan alat ini hanya bisa dimainkan oleh saikong (pemimpin doa).

\section{Terompet}

Terompet cina adalah alat musik yang terbuat dari logam kuningan. Alat musik ini memiliki tujuh lubang yang terletak dibagian sisi batang dan cara memainkanya ditiup. Alat musik terompet cina ini dimainkan oleh 
pemain musik dan bukan dimainkan oleh saikong (pemimpin doa), serta fungsi alat musik ini sebagai pembawa melodi.

\section{Kecapi Cina}

Kecapi Cina adalah alat musik yang terbuat dari kayu yang memilki senar, Kecapi Cina ini berbentuk seperti meja kecil. Cara memainkannya dipukul, alat pemukul itu sendiri terbuat dari kayu yang tipis dan ujung kayu tersebut dilapisi gabus. Alat musik kecapi cina ini dimainkan oleh pemain musik dan bukan dimainkan oleh saikong serta fungsi alat musik ini juga sebagai pembawa melodi.

\section{Biola Cina}

Biola Cina adalah alat musik yang terbuat dari kayu yang memilki senar, dan Biola Cina ini berbentuk seperti biola pada umumnya. Cara memainkannya digesek, namun ada sedikit perbedaan dalam memainkan biola pada umumnya. Biola Cina tersebut dimainkan berdiri searah tubuh pemainnya.

\section{Gendang}

Gendang adalah alat musik terbuat dari kayu yang berbentuk lingkaran dan permukaan atas kayu dilapisi oleh kulit lembu. Cara memainkannya dipukul, dan alat pemukul itu sendiri terbuat dari kayu.

Bentuk penyajian Musik Dalam Upacara Thau Chit Pada Agama Khonghucu di Yayasan Budi Mulia Kecamatan Lubuk Pakam Kabupaten Deli Serdang

1. Musik untuk penghormatan kepada dewa-dewa

Pada proses upacara tersebut, musik tersebut dimainkan pada saat ritual Huat Piau. saikong (pemimpin doa) membunyikan lonceng sebanyak empat kali kemudian saikong membacakan doa dari kitab suci. Musik tersebut berisikan tentang penghormatan kepada seluruh dewa agar upacara yang akan dilaksanakan berjalan dengan baik

2. Pemberitahuan Kepada Roh

Musik tersebut dimainkan pada saat ritual Tiau Hun. Doa yang dibacakan saikong berisikan tentang pemberitahuan dan penghormatan kepada roh yang dilakukan oleh keturunannya.

3. Musik Pengembalian Roh

Musik tersebut dimainkan pada saat ritual Koei Kio. Musik yang ketiga ini berisikan tentang 
pengembalian roh kepada dewa.

Dalam ritual ini, saikong beserta seluruh keturunan orang yang telah meninggal melakukan perjalan yang melewati sebuah susunan papan yang telah di bentuk berupa jembatan. Pada proses ini umat agama Khonghucu meyakini bahwa di dunia roh, ada sebuah jembatan yang harus dilewati setiap roh untuk sampai menuju surga.

Fungsi Musik Dalam Upacara Thau Chit Pada Agama Khonghucu di Yayasan Budi Mulia Kecamatan Lubuk Pakam Kabupaten Deli Serdang

a. Fungsi Kenikmatan Estetika dan Pengungkapan Emosional

Terdapat fungsi musik sebagai kenikmatan estetika musik dalam upacara Thau Chit, dimana masyarakat penganut agama Khonghucu menikmati keindahan alunan melodi dan pengungkapan emosional bagi masyarakat penganut agama Khonghucu pada upacara Thau Chit, dimana masyarakat sangat berfokus dalam mengirimkan doa kepada salah seorang keluarganya yang telah meninggal. b. Fungsi Komunikasi dan

Pengesahan Ritual Keagamaan

Dalam upacara Thau Chit, sebelum musik dimainkan selalu didahului dengan doa sambil memukul lonceng. Mereka meyakini bahwa doa yang mereka sampaikan akan sampai melalui bunyi lonceng tersebut.

c. Fungsi Kontribusi Terhadap

Kelangsungan dan Stabilitas

Budaya.

Musik memberikan kontribusi dan stabilitas budaya karena adanya sejarah dari masyarakat penganut agama Khonghucu yang menunjukkan kelangsungan budaya, melalui permainan alat musik pada upacara Thau Chit.

\section{PENUTUP}

Dari hasil penelitian dan pembahasan yang telah di deskripsikan pada bab sebelumnya maka diperoleh kesimpulan:

1. Dalam proses tata Upacara Thau Chit pada agama Khonghucu seluruh umat agama Khonghucu yang bertempat tinggal di Kecamatan Lubuk Pakam masih tetap menjalankan tradisi yang diwariskan oleh leluhur mereka seperti tata cara upacara, Huat Piau (pembersihan 
altar dan pengiriman surat kepada dewa neraka), Pai Wang (penghormatan kepada dewa-dewa surga). Phou Tua (mengundang dewa bumi), Tiau Hun (pemanggilan roh), Mong Ek (memandikan roh), Pai Iok Wang (penghormatan kepada dewa obat), Sio Ui (pembakaran rumah roh) Dan Koei Kio (pengembalian roh) yang merupakan sebagai ritual penutup.

2. Alat musik yang digunakan dalam mengiringi upacara Thau Chit dapat diklsifikasikan berdasarkan sumber bunyi yaitu, lonceng dan simbal/la bua merupakan jenis alat musik Idiofone yang berfungsi sebagai pembawa tempo. Trompet cina/Choei merupakan jenis alat musik Aerofone, sedangkan kecapi cina/Khin dan biola/Er $\mathrm{Hu}$ merupakan jenis alat musik Chordofon dimana pada alat musik tersebut berfungsi sebagai pembawa melodi. Sedangkan gendang merupakan jenis alat musik Membranofone yang berfungsi sebagai pembawa ritmik yang dapat memberikan rasa semangat dalam upacara tersebut. Dari seluruh Instrument yang dimainkan pada upacara Thau Chit, lonceng yang dimainkan oleh saikong (pemimpin doa) merupakan hal yang terpenting dan wajib pada saat proses pelaksanaan kegiatan upacara tersebut, karena alat musik tersebut memiliki fungsi bukan hanya sekedar pembawa tempo tetapi juga dapat menjadi media komunikasi kepada dewa yang dapat mewakili seluruh instrument yang lain.

3. Bentuk penyajian musik Dalam upacara Thau Chit pada agama Khonghucu di Yayasan Budi Mulia Kecamatan Lubuk Pakam Kabupaten Deli Serdang memiliki tiga bagian yaitu, musik penghormatan kepada dewa-dewa, pemberitahuan kepada roh,dan pengembalian roh.

4. Fungsi musik dalam tata upacara Thau Chit pada agama Khonghucu di Yayasan Budi Mulia Kecamatan Lubuk Pakam Kabupaten Deli Serdang sebagai media komunikasi kepada roh seseorang yang telah meninggal dan juga sebagai media umat agama Khonghucu dalam menghormati seluruh dewa-dewa yang mereka sembah. 


\section{Saran}

Dari beberapa kesimpulan di atas, peneliti mengajukan saran-saran sebagai berikut:

1. Penggunaan alat musik tradisional dalam upacara Thau Chit diharapkan tetap dilestarikan dan dikenalkan kepada generasi muda khususnya generasi muda agama Khonghucu.

1. Hendaknya setiap yayasan sosial membuat suatu pelatihan khusus dalam menarik minat kepada generasi muda untuk mempelajari musik tradisonal Khonghucu yang telah diwariskan oleh leluhur mereka.

2. Memberikan pembelajaran dan motivasi kepada generasi muda untuk lebih mencintai budayanya sendiri.

\section{DAFTAR PUSTAKA}

A. Marcus. S. 2002. Hari-Hari Raya Tionghoa. Jakarta: Marwin.

Arikunto,Suharsimi.2005.Manajemen Penelitian.Jakarta: Bhineka Cipta.

Banoe. Pono. 2003. Kamus Musik. Jakarta: Kanisius.

Buchari.2004.Belajar mudah penelitian untuk guru-Karyawan dan peneliti

Pemula.Bandung:Alfabeta.

Bungin, Burhan.2008.Penelitian Kualitatif. Jakarta : Kencana.

Djelantik. 1999. Estetika Sebuah Penganta. Bandung: Masyarakat Seni Pertunjukan Indonesia.
Djohan. 2005: Psikologi Musik. Yogyakarta: Buku Baik.

Endang, Eva. 2010. Peranan Musik Dalam Kebaktian Agama Buddha Di Viara Sahassa Buddha Medan. Universitas Negeri Medan. Skripsi.

Fieser, James. 2004. Scriptures Of The East. New York.

Gunawan, Imam. 2013. Metode Penelitian Kualitatif. Jakarta: Bumi Aksara.

Hadeli. 2006. Pedoman Penelitiaan Kualitatif. Jakarta: Kencana.

Hadi. Sumadyo. Y. 2003. Seni Dalam Ritual Agama. Yogyakarta: Yayasan Untuk Indonesia.

Hidayat. 2007. Metode Penelitian Kuantitatif. Jakarta.

Ikhsan M. Tanggok. 2000. Jalan Keselamatan Melalui Agama Khonghucu. Jakarta: PT. Gramedia Pustaka Utama.

James, Spradliy. 2008. Partisipants Observation. Rinehart and Wiston.

J. Lexy. 2006. Metode Penelitian Kualitatif. Bandung: PT. Remaja Rosdakarya Offset.

Kartono. 1990. Psikologi Belajar. Bogar: Proyek Pembinaan Pendidikan.

Koentjaraningrat. 2004. Manusia dan Kebudayaan di Indonesia. Jakarta: Djambatan.

Kennedy, Michael.1995. Oxford (Concise dictionary of Music ) Oxford University Press.

Langer,Suzanne,K.1998.Problems of art, terjemahan F.X Widaryanto, Bandung: Akademi Seni Tari Indonesia. 
Maryaeni. 2005. Metode Penelitian Kebudayaan. Jakarta: Bumi Pustaka

Muttaqin, Moh.(2008). Musik Klasik (Pengantar Musikologi untuk SMK). Jakarta: Pusat Perbukuan Pendidikan Nasional.

Pasaribu, Ben M. 2004. Musikalitas + Etnisitas $=$ Pluralitas Dalam Musik Etnik.

Sembiring, Dolorosa, M. 2011. Peranan Musik Dalam Upacara Keagamaan Dewa Yadnya Pada Masyarakat Hindu Bali di Pura Agung Raksa Bhuana Medan. Universitas Negeri Medan. Skripsi.

Shaputra, Irvan, M. 2003. Upacara Kematian Dalam Masyarakat Cina Indonesia (artikel).

Sinambela, Bertua Naomi. 2011. Peranan Musik Pada Tata Ibadah Agama Buddha Mahayana di Vihara Borobudur jalan Imam Bonjol Medan. Universitas Negeri Medan. Skripsi.

Soeharto. M. 1992. Kamus Musiki . Jakarta :Gramedia Widia Sarana Indonesia.

Soeharto. 2001. Musik Dalam Mencerdaskan Anak. Jakarta: Cakrawala. Spradly, James.2008.Participant Observation.Rinehart and wiston.

Sugiono.2008. Metode Penelitian Kuantitatif dan $R \& D$. Bandung: alfabeta .

2009. Metode Penelitian Kuantitatif dan $R \& D$. Bandung: alfabeta.

2010. Metode Penelitian

Kuantitatif dan $R \& D$. Bandung: alfabeta.
. 2012. Metode Penelitian Kuantitatif dan kualitative $R \& D$. Bandung: alfabeta.

Soedarsono.1999.Seni Pertunjukan Indonesia di Era Globalisasi. Jakarta: Direktorat Jenderal Pendidikan Tinggi Departemen Pendidikan dan Kebudayaan.

Supranto. 2004. Metedologi Penelitian Kependidikan. Bandung: Publishing House.

Surakhmad, Winarno. 1982. Pengantar Penelitian Ilmiah. Bandung: Tarsito.

Suyanto, dkk. Metodologi Penelitian Sosial. Jakarta: Kencana.

Tampubolon, Dian P. N. 2009. Peranan Musik Dalam Ritual Agama Hindu Di Kuil Shri Mariamman Koil Kampung Madras Medan. Universitas Negeri Medan. Skripsi.

Tanggok, Ikhsan, M. 2005. Mengenal Lebih Dekat Agama Khonghucu di Indonesia. Pelita kebajikan. Jakarta.

Thaddeus, George, Jones (1974). Music Theory. Lodon.Barnes and Noble Book.

Walter, E, Nallin (1968). The Musical Idea. London. United States of America.

Webber, Max. 1951. The Relegion of China. United States of America.

Soeharto. M. 1992. Kamus Musiki . Jakarta :Gramedia Widia Sarana Indonesia. 